\title{
Adopting Virtual Classes during the COVID-19 Lockdown: Interrogating New Approaches to Teaching and the Exclusion of Learners in Rural Settings
}

\author{
Raphael Nhongo* \\ North-West University, Mafikeng, South Africa \\ Liqhwa Siziba \\ North-West University, Mafikeng, South Africa
}

\begin{abstract}
A variety of instructional strategies were devised to ensure continuity in education during the COVID-19 lockdown. This paper interrogates the exclusion of learners in rural settings of Zimbabwe as a result of the methods of teaching that were adopted by the government during the COVID-19 lockdown. The paper seeks to answer the question; how are the strategies meant to ensure continuity in education during the lockdown excluding learners in rural settings? The strategies that were adopted by the government have been identified to be contributing to the exclusion of learners in rural settings. Data was collected through semistructured interviews from 20 teachers who teach in rural areas at two of Zimbabwe's ten provinces. The interviews were done as a follow-up to the approaches of remote teaching adopted during the lockdown. The study argues that the adoption of uniform approaches to teaching and learning throughout the country during COVID-19 lockdown would not suffice as the functionality of each approach depends on the infrastructure and the economic conditions characteristic of each particular geographical location. The strategies adopted during the pandemic in a low-income country like Zimbabwe should not be permanent but should simply be an emergency response. Learners in rural settings are bound to be excluded in education during the pandemic if policymakers enact 'one size fits all' approaches meant for abrupt implementation. Strategies that suit the idea of emergency remote teaching during the pandemic are the most favourable.
\end{abstract}

Keywords: COVID-19; virtual classroom; exclusion; lockdown; rural settings

\footnotetext{
*Corresponding author: Raphael Nhongo, raphaelnhongo@gmail.com
} 


\section{Introduction}

For education to continue in schools during the COVID-19 lockdown, various measures were suggested with some taking effect and some remaining as proposals. The proposed actions were to facilitate instruction through online classrooms, to deliver lessons via radio and also to have the lessons conducted via social media, specifically WhatsApp. However, the implementation of these teaching and learning approaches in Zimbabwe's schools were associated with several challenges. Such challenges included unfamiliarity with Information and Communication Technology (ICT), access to gadgets for sending and receiving lessons, network accessibility, availability of electricity and affordability of data to access the information. However, in noticing these shortcomings, the Ministry of Primary and Secondary Education (MPSE) proposed the use of radio in lessons delivery for primary and secondary school learners in addition to online classrooms. The MPSE also identified learners in rural settings as the ones facing more challenges and there was a need therefore, to also avail hard copies of lessons broadcast on radio. In a live broadcast interview on South African television station, SABC 1 on 04 May 2020, James Elder, the representative for United Nations International Children's Emergency Fund (UNICEF) in Southern Africa outlined a strategy by his organisation to negotiate with governments in his jurisdiction to support and implement the use of radio for conducting lessons during the COVID-19 induced school closures.

The paper looks at how remote teaching excludes learners in rural settings of Zimbabwe, specifically those in the southern parts of the country in Matabeleland North and Matabeleland South provinces. UNICEF has observed that in Eastern and Southern Africa, internet accessibility is constrained as only one in five (22\%) households have access to the internet. In comparison, $84 \%$ of the rural people, where the majority of learners reside, have no access to electricity (UNICEF, 2020). Most rural communities in Zimbabwe are underserved or unserved at all concerning radio signals (Barakabitze et al., 2019; Gwaka et al., 2018; Sunil, 2021). Because of the challenges related to limited or no internet connectivity and radio signal in rural areas, it is therefore prudent to investigate the exclusion of rural learners in education during the COVID-19 induced lockdown. The study analyses the approaches that were proposed and adopted in Zimbabwe with the main focus being to outline how remote teaching excludes learners in rural communities. This study shows that learners in rural areas continue to be excluded in remote teaching during the COVID-19 lockdown because the MPSE did not consider the state of ICT infrastructure and the economic conditions in rural settings as compared to urban areas. Predecessor studies have recommended online teaching as the most immediate solution for ensuring continuity in education during a crisis. However, this study suggests that before the adoption of any remote teaching and instructional strategy, a pre-assessment of available resources is required. The paper also advocates for the adoption of varied instructional strategies informed by the state of ICT infrastructure and the prevailing economic conditions. The discussion begins by looking at experiences of China and South Africa in ensuring continuity in education during school closures. 


\section{New Instructional Approaches during the Covid-19 Induced School Closures}

The COVID-19 induced school closures have been more serious because they affected all schools in the world, unlike during other pandemics where education in specific countries was affected. The 1918 influenza pandemic which had devastating effects stretching from 1918 to 1919 took the lives of 50 to 100 million people worldwide (Gallo \& Trompetto, 2020; King \& Londrigan, 2021; Krishnan et al., 2020; Liang et al., 2021; Owusu-Fordjour, Koomson, Hanson, 2020; Psacharopoulos et al., 2020). It has been proven that the 1918 influenza was more deadly than the COVID-19 pandemic (King \& Londrigan, 2021; Lee \& Rhee, 2021; Liang et al., 2021; Scarpa et al., 2020; Yamin, 2020). Yamin (2020) points out that historically, the first corona virus surfaced in 1965 with symptoms of common cold and thereafter, five different strands of this virus emerged. Before COVID19, the most severe of these viruses was the Severe Acute Respiratory Syndrome (SARS), which infected about eight thousand people and took the lives of around 800 (Yamin, 2020). At the end of 2002, China implemented a variety of measures including stopping face-to-face instruction in some parts of the country to curtail the spread of SARS (Cauchemez et al., 2014; Huang et al., 2020). Similarly, in 2009, the outbreak of H1N1 Flu did not spare the education sector in countries that include China, Italy, Serbia, New Zealand, Thailand, and United States (Cauchemez et al., 2014; Huang et al., 2020). The closure of schools as a result of H1N1 Flu was shorter than the time that it has taken with COVID-19 so far. Governments, worldwide implemented school closures as a way of controlling the spread of COVID-19 in early 2020 (Burzynska \& Contreras, 2020; Viner et al., 2020). History shows that the only time that Zimbabwe closed schools was from 1977 to 1980 as a result of the liberation struggle (Kriger, 1988; Nhongo \& Tshotsho, 2021). It is vital to begin by looking at the experiences of other countries to understand how they adopted new approaches to ensure continuity in education during the COVID-19 induced lockdown. China's experience is particularly essential for this study, as some of its methods and approaches were used to analyse those adopted by Zimbabwe. South Africa's lessons were also reviewed to make a pre-exposure of the challenges that result in the exclusion of rural learners.

There is strong evidence shared worldwide which suggests that the first cases of COVID-19 were detected in the Chinese city of Wuhan, also identified as the epicentre of the pandemic before it spread to other parts of China and the rest of the world. China was the first nation worldwide to provide remote instruction to hundreds of millions of learners during the COVID-19 pandemic (Huang et al., 2020). The government of China initiated many emergency strategies for managing COVID-19. These included social distancing and the subsequent closing of schools (McAleer, 2020; Wang et al., 2020). The government of China launched the "Disrupted Classes, Undisrupted Learning" plan (Huang et al, 2020) also referred to as the "Suspending Classes Without Stopping Learning" strategy (Zhang et al., 2020). This plan was meant to ensure continuity in education during the lockdown period by providing easily accessible online education to above 270 million learners from home (Huang et al., 2020; Zhang et al., 2020). While the two concepts, "Disrupted Classes, Undisrupted Learning" and "Suspending Classes 
Without Stopping Learning" carry the same meaning, the variation in terminology could most probably be explained in terms of the approaches that were involved in Chinese-English translation.

In implementing teaching and learning through the "Suspending Classes Without Stopping Learning" strategy (Zhang et al., 2020) or "Disrupted Classes, Undisrupted Learning" (Huang et al., 2020), the government of China took five steps to implement the plan:

1. The government of China made efforts in implementing the provision of reliable network. The Education Ministry and several telecom operators worked together in developing the online teaching platforms. China approved 37 organisations and internet providers to provide online educational platforms.

2. Training of teachers. China's department of education got seriously involved in training and preparing teachers for online instruction. Localised training of teachers was also organised by the schools in complementing the government's initiative.

3. It was enabling schools and local authorities to provide online instruction with available resources. To ensure accessibility of knowledge and resources to all learners, particularly those in rural areas, China used satellite television receivers to reach out to those without internet coverage.

4. It was formulating plans for preparing learners for post-COVID return to school. The development of courses that taught learners about the pandemic was initiated.

5. It was working on guidelines for school reopening after the pandemic. The government put in place a plan to have schools opening in a staggered manner (Zhang et al., 2020).

The plan adopted by China could be adopted by other countries, including Zimbabwe. Zimbabwe is characterised by network problems as will be shown in the discussions. These challenges end up being a potential to exclude learners in areas with network problems. There is need therefore, for the government to engage various network providers such as Econet, Netone, Telecel and Powertel to avail affordable data packages and also partner with the government in improving ICT infrastructure.

As of 23 May 2020, South Africa was the hardest hit African country with 21,343 cases of COVID-19, followed by Algeria with 8,308 cases, and Lesotho being the least affected with only 1 case. South Africa adopted a variety of measures to ensure continuity in education during the lockdown, and those measures were dominated by online teaching and learning just like China and other countries in the world. Dube (2020) reflected on the problems faced by learners in rural settings in South Africa during the COVID-19 lockdown. Dube (2020) was looking at problems faced by learners in the adoption of new approaches to teaching, while the current study is looking at how similar problems result in the exclusion of learners in rural settings. However, this study is similar to the one done by Dube (2020) in that they both reflect on problems faced in rural settings in the 
education sector during the COVID-19 lockdown. Dube (2020) argues that learners in rural settings face unprecedented problems in transitioning to a 'new normal' in education. Similarly, Mahlaba (2020) highlights the importance of selfdirected learning during the COVID-19 pandemic. Ramrathan (2020) focused on the South African education during the COVID-19 pandemic and argued for a curriculum that is relevant and responsive to the issues and challenges of the country within a global world. While the South African government is promoting online education as the only option during COVID-19, this model excludes the bulk of learners in rural settings from accessing education, due to a lack of devices to access the internet and low-tech software (Dube, 2020). In addition to the challenges faced by learners, Dube (2020) also focused on the exclusion of rural leaners in South Africa. Molise and Dube (2020) note that emergency online teaching (EOT) was adopted in South Africa during COVID-19 school closures as a way of ensuring continuity in education. The idea behind the adoption of EOT was informed by the realisation that some teachers were incompetent in ICT, while others were inexperienced, all this in addition to poor internet connectivity (Molise \& Dube, 2020; Mukuna \& Aloka, 2020). The results of their study revealed that EOT is desirable and doable, especially in rural schools.

The implementation of online teaching has not been without challenges in many countries around the world. Al-Naabi and Al-Abri (2021) did a cross-sectional survey where they wanted to hear the perceptions of teachers about the implementation of ERT during the COVID-19 lockdown at Omani higher education. The findings of their study indicated that teachers' academic qualifications and prior experience influenced the success of e-learning practices. A similar study was carried out by Batac et al. (2021) who looked at teachers' perceptions, experiences and insights in using blended learning during the COVID-19 pandemic in the Philippines. In using blended learning, the teachers experienced challenges such as readiness, technology literacy, financial difficulties, health risks and access to technology (Batac et al., 2021). Alghamdi and Al-Ghamdi (2021) researched on elementary teachers' thoughts about distance education and learning twenty-first century skills during COVID-19 pandemic. The results of the study showed that the research participants were for the idea of transformation of knowledge and resources used in teaching and learning in the modern era (Alghamdi \& Al-Ghamdi, 2021). The current study investigates challenges that are faced in implementing ERT in rural schools.

\section{Emergency Remote Teaching as an Ideal Strategy}

The arguments raised in this paper are guided by emergency remote teaching (ERT) as a conceptual idea. According to Hodges et al. (2020), ERT entails temporarily shifting from the usual instructional method to the adoption of educational support that is reliable, instant and manageable. ERT is temporary but requires the use of different strategies and priorities from those of traditional face-to-face teaching (Bozkurt \& Sharma, 2020). The main feature of ERT is that it uses fully remote instructional strategies that is normally delivered face-to-face, that would return to the traditional format once the pandemic is over (Hodges et al. 2020). ERT does not necessarily require a recreation of a robust educational 
system, but it involves the promotion of temporary access to instruction through the use of readily available resources and infrastructure.

ERT does not require expensive and complex intervention strategies but it simply utilises readily available, affordable and accessible resources. Although online teaching can be part of ERT, where ICT infrastructure is developed, it should be noted that it is not always the case that online teaching can be ERT especially in developing countries like Zimbabwe where there is poor ICT infrastructure. According to Aguliera and Nightengale-Lee (2020), ERT can be distinguished from online teaching in that ERT is an abrupt shift from classroom based instruction and accommodates strategies that do not require too much planning. ERT should not be labelled as online teaching considering existing and known diversity in educational approaches (Talidong, 2020). Designing a robust online learning curriculum and putting up adequate ICT infrastructure would take time before it can be operational to enable learners to access instructional material (Toquero, 2020). Zimbabwe is in a 'crisis within a crisis' because while it is facing the COVID-19 pandemic, it is at the same time experiencing serious economic hardships. Trying to set up online teaching as a strategy for providing instruction across the country during the COVID-19 school closures would remain a pipe dream in Zimbabwe. ERT affords educators freedom and flexibility to choose from a variety of instructional options in the midst of a crisis (Toquero, 2020).

The study uses ERT as an approach to show that the strategies for ensuring continuity in teaching and learning in Zimbabwe require consideration of accessibility, availability and affordability of resources to be used. ERT requires pre-assessment of available resources so that there is minimal disruption to continuity in teaching and learning during school closures. We use ERT here to assess the three strategies which are online teaching, teaching through radio, and the use of WhatsApp; and to reveal how the adoption of these strategies excluded and included learners from rural settings in Zimbabwe.

\section{Methodology}

In pursuit of unravelling how the new instructional approaches excluded learners from rural settings, a qualitative phenomenological research design was used. The paper looks at how the three instructional strategies for remote teaching that Zimbabwe adopted during the COVID-19 lockdown resulted in the exclusion of learners in rural settings. The phenomenological design requires that interviews be employed in order to understand human experiences (Creswell, 2017). Semistructured interviews with 20 teachers from 20 schools in Matabeleland South and Matabeleland North provinces in Zimbabwe were conducted. The semistructured interviews were conducted with teachers from both primary and secondary schools on how the new approaches to teaching and learning as a response to the COVID-19 lockdown excluded or had the potential to disadvantage rural learners. The strategies that were identified to be in use included online teaching, the radio and WhatsApp. All these approaches excluded rural learners in a variety of ways, the major challenge being that of spontaneously devising and implementing the new strategies. 
The 20 teachers were interviewed through WhatsApp and phone calls depending on the channel preferred by the research participant. These methods were used because the interviews were conducted during the COVID-19 lockdown when movements were restricted. The major criteria for selecting teachers was that they taught at a rural school that falls in either Matabeleland South or Matabeleland North. These research participants were selected through purposeful sampling and snowball sampling. Purposeful sampling sometimes referred to as judgemental sampling is where research participants are selected because they have specific characteristics that are ideal for the research (Vehovar et al., 2016). Snowball sampling is where research participants with similar characteristics create a network that makes it ideal for the researcher to identify them (Vehovar et al., 2016). Although a total of 20 teachers were interviewed, the data presented came from only 12 teachers since they are the ones that provided data which is suitable for this paper.

As an ethical procedure, the real names of research participants were not used in data presentation and discussion, but rather, pseudonyms were used. Table 1 below shows the pseudonyms that were used to anonymise the research participants. Clearance was sought from MPSE before interviewing the teachers. The data gathered from the research participants was destroyed soon after the publication of this paper.

Table 1: Pseudonyms for research participants

\begin{tabular}{|c|c|}
\hline CODE & PSEUDONYM \\
\hline 1 & Slie \\
\hline 2 & Sibo \\
\hline 3 & Nana \\
\hline 4 & Mpue \\
\hline 5 & Daisy \\
\hline 6 & Nothando \\
\hline 7 & Mamba \\
\hline 8 & Talan \\
\hline 9 & Tawa \\
\hline 10 & Mpo \\
\hline 11 & Nicky \\
\hline 12 & Angy \\
\hline
\end{tabular}

\section{Exclusion of Rural Learners through Remote Teaching}

The approaches that have been adopted in teaching and learning as a response to COVID-19 lockdown call for remote instruction. Hodges et al. (2020) note that researchers in educational technology have referred to the types of modes of education that fall under remote teaching as distance learning, distributed learning, blended learning, online learning and mobile learning. However, Hodges et al. (2020) proposed "emergency remote teaching" to refer to instructional methods of delivery during the pandemic.

\subsection{Online Learning}

Online learning can take place in synchronous or asynchronous situations using a variety of ICT devices such as mobile phones, tablets, laptops and desktops with 
internet access. Synchronous learning is a more structured instructional method where the subjects take place in real-time in live virtual classroom settings (Casey et al., 2018). In asynchronous classes, students cannot get feedback instantly and instructional material is not provided in real-time classes, but on different learning management platforms (Casey et al., 2018).

The MPSE of Zimbabwe recommended the adoption of the use of a platform called Ruzivo as a way of providing instruction to learners during the COVID-19 lockdown. Ruzivo is a subsidiary of Higherlife Foundation and works in partnership with the MPSE (Ruzivo, 2020). It is an online instructional platform targeting both primary and secondary school learners (Ruzivo, 2019). Ruzivo was not established as an emergency remote teaching platform to cater for education during the COVID-19 lockdown, but it was set up through Higherlife Foundation in 2019. Higherlife Foundation's mandate is to uplift education from the grassroots up to tertiary level without excluding learners from rural settings (Ruzivo, 2019). Ruzivo is learner-centred, and knowledge is personalised, allowing each learner to work at their own pace without their teacher and get immediate feedback on completed exercises. Although this platform was designed to reach out to learners in rural areas, the same learners whom it was intended for are excluded because it requires internet for one to use it. Both the internet and the devices to access Ruzivo are not readily available in rural areas, rendering this platform a preserve of a very few learners in rural settings.

For online learning to take place, learners require gadgets such as smartphones, tablets, laptops or desktops. They also need internet access, data and electricity. However, all these materials and services are not easily accessible to rural learners since the majority of them come from disadvantaged backgrounds. The teachers indicated that learners in rural areas could not afford to buy devices for accessing learning material online. Slie, indicated that "relevant gadgets in rural areas are the old model type of cell phones, few have smartphones, cost and maintenance of these gadgets is also high". On the other hand, Sibo registered her observation that "Some learners do not have the gadgets for online teaching like phones and laptops. Parents do not have money to buy the gadgets". Mpue, said "Computers are available at the school but learners do not have access to the school because of the lockdown, so they remain excluded in online learning". Nana's opinion was that "Some people in rural areas do not have smartphones and data is expensive plus with this COVID-19, movements are limited hence no helping hands from the neighbours". These observations by teachers indicate that learners in rural settings are excluded from online learning because they do not have devices to access online classes.

The unavailability of mobile network and electricity to power the devices also play a massive role in the exclusion of learners from online teaching in rural settings. To this end, Daisy noted that:

In Beitbridge West, Zimbabwe's network is a challenge. In most areas such as Dombo, Madali, Mtangamchena, Masera, Toporo there is no network at all. Shashe also has no network at all...Parents are relying on South African networks which at times cut off, hence online learning might be a challenge to the rural child. 
Nothando gave the following detailed account:

Online teaching can be a great challenge to rural schools. Let's consider schools like Gomoza Primary where there is no electricity. For instance, there is an NGO called Profoture, which donated ICT gadgets such as tablets, laptops and projectors. They wanted to ensure that the school embraces technology in all aspects, but we are failing to make use of those gadgets because we don't have electricity. Moreover, there is a network problem at Gomoza, so doing online teaching can also be a challenge as it requires one to have network access. Learners in Gomoza are also ICT illiterate since they have less exposure to ICT tools. Learners can't even do simple things such as switching on a smartphone because they are rarely exposed to smartphones, so online learning can be challenging.

Mamba said:

Online teaching is a real challenge to most rural areas. For example, in Gokwe South, schools like Kasuwe, Ngani, Manyoni, Chamatendera, Huchu, Masosoni and Chireya Simuchembu 1 and 2 in Gokwe North just to mention a few have no electricity.

Sibo put it in the following words:

There is no network coverage in this area. We use Botswana network Mascom and Orange, whose airtime and data are expensive to buy using Pula. Most learners are not computer or ICT literate. The network can only be accessed at specific locations and one has to go to that point to access what material online.

Talan from Matabeleland South revealed that:

Poor network and the unavailability of mobile network services are some of the challenge faced. Some places still do not have viable network system and if it's to be done online, those on the digital divide won't access the lessons. In Silozwe network is so poor such that one cannot even open google. So online education will be for those with, then those without network. Access to network will only be for those with gadgets and money, meaning online education is only going to embrace the elite mostly and ignore the plight of the poor and those on the digital divide.

The problems of network availability and access to electricity coupled with lack of knowledge of the use of ICT tools exclude rural learners from online instruction.

It was also pointed out that in areas where mobile network is available, learners can still be excluded from online learning because they cannot afford mobile data. The teachers indicated that parents and guardians whom learners depend on for financial support were caught unprepared by the closures of schools and therefore had no money to buy data to support online learning. Zimbabwe is facing an economic crisis, and the people in the rural areas who are dependent on subsistence farming are the hardest hit after the country received poor rainfall during the 2019-2020 farming season. Tawa revealed that: 
Most parents in Vulindlela in Ward 16 are dependent on peasant farming for their survival. So the absence of rain affected their produce heavily meaning that whatever they got will be channelled towards basic commodities. Online teaching will be a difficult thing to implement since no resources will be channelled towards its implementation.

Echoing the same sentiments, Angy retorted that:

Even though some are on a viable network and have phones, they still won't manage to access online lessons because of unaffordability of data. Most Zimbabweans are poor, and parents won't sacrifice the little they earn for their children to be online, they would rather chase the expensive basic commodities. Furthermore, the Silozwe community relies on selling craftwork to tourists, and lockdown means no tourist visits and no means of income to parents.

What exacerbates the situation is the frequent and ad hoc upward review of data prices. For instance, on the $5^{\text {th }}$ of May in 2020, in the midst of a hard lockdown, mobile network operators hiked the price of data bundles by up to 225\% ("Econet raises data", 2020).

Online learning has been confused with ERT, and that is the reason why it is challenging to implement it during the COVID-19 crisis in Zimbabwe. Online learning excludes learners in rural settings because it is applied under conditions and in contexts it is not suited. Policymakers opt for the implementation of policies in a 'one size fits all' approach throughout the whole country, yet some contexts require tailor made approaches specific to their unique conditions. This preferred approach results in some of these strategies not getting operationalised especially in contexts where they are not well suited. The MPSE, as an arm of government has to consider the extent to which the ICT infrastructure is developed in the rural areas before settling for online teaching as a nationwide strategy. ERT would not consider online teaching as a possible strategy in rural settings because the available ICT infrastructure is underdeveloped. Aguliera and Nightengale-Lee (2020) argue that marginalised communities in rural areas need to be afforded ERT that utilises readily available resources. In rural areas where ICT infrastructure is poor, there is need to consider other instructional strategies that are not necessarily online teaching.

\subsection{Learning through Radio}

Although most rural areas have no access to the internet, some of them do have access to a radio signal. In realising that learners in rural areas were going to be excluded if online teaching was to be taken as the only approach in delivering instruction during the lockdown, the government of Zimbabwe proposed the broadcasting of lessons through the radio. To cater for those without radio receivers, it was suggested that learners from rural schools be availed with hard copies of lessons broadcast on radio. The government through MPSE revealed that it had reached an agreement with Zimbabwe Broadcasting Corporation (ZBC) to have lessons delivered through radio (Gono, 2020). It was also revealed that printed material to complement radio lessons was going to be distributed to 
those areas without radio signal (Gono, 2020). However, it was not clear when exactly the airing of lessons on the radio would start.

UNICEF also pledged to provide assistance to governments in Southern Africa to capacitate them for the implementation and dissemination of lessons through radio (UNICEF, 2020). UNICEF also assured Zimbabwe that those learners who have no access to radio signal would benefit from printed material (UNICEF, 2020). The efforts made by UNICEF are the same as those proposed by the government of Zimbabwe which shows that Zimbabwe is banking on the teaching and learning programmes that are rolled out by UNICEF.

The teachers also concurred that radio was the best platform for delivering lessons because learners without receivers can substitute them with simple, and cheap cell phones as radio receivers. The teachers noted that although lesson delivery through radio had several advantages, it also had its own disadvantages. For instance, Mpo observed thus:

The option by the government to offer lessons through the radio is much better but in our case as it is in other neighboring schools, this is again a non-starter. Yes, almost every home has a radio but just for playing recorded music as the channels are unreachable as well. The FM radio stations are only better accessible when one is on top of a mountain. Then the question is, how many times will a person climb a mountain to get access to radio signal?

Nicky, the head of one of the schools said:

I am the head of the school and my home is closer to the school but I have not received any teaching or lessons material. I only read about it in the newspapers where the minister was talking about areas like ours where there are no radio waves. We are still waiting for those booklets maybe they will come one day.

The other challenge was that there was going to be limited time for interactive engagement between learners and instructors for further explanations and clarifications. Learners in rural areas could be excluded in that they may not have access to a network to make calls for clarification and airtime cost remains a severe challenge for them. Odera (2011) observes that radio is one of the most effective and affordable educational technologies available in developing countries in Africa. When considering, ERT, radio sounds as the best option for rural settings but the challenge is that some areas do not have radio signal while some learners do not have access to radio receivers.

\subsection{WhatsApp as a Learning Platform}

Despite being familiar and accessible to many even in rural areas, WhatsApp is treated with scepticism as a formal learning platform that can compete with online teaching and traditional face-to-face method. Although teachers have always been discouraged from using social media as a teaching platform, WhatsApp has however, gained popularity as an instructional method during the lockdown. As our societies move towards advancements in information sharing, education is one area that faces challenges in making sense of this transition (Ostashewski \& 
Reid, 2013). The teachers who were interviewed particularly those teaching examination classes reported that they never stopped teaching upon school closures as they continued engaging with learners through WhatsApp. The teachers mentioned that although WhatsApp was not a formal instructional method, it was however, more effective than all the other methods of remote teaching. There is a need to explore ways in which WhatsApp can be formalised as an acceptable platform for teaching and learning since it is easily accessible. While WhatsApp has proven to be more convenient than other platforms that require internet, it should, however, be borne in mind that some rural areas still have no mobile network coverage. It has to be noted again that in rural areas, not all learners can afford smartphones that are compatible with the WhatsApp application.

The teachers said that although WhatsApp was a convenient method for instruction and lesson delivery, its major challenge was mobile network accessibility, affordability of data and access to smartphones. Mpo said:

Although WhatsApp is a very effective way, network coverage is the greatest barrier. It may be faster in reaching the learners but there is no reliable network coverage. Another impediment is the cost of bundles. With our school and other surrounding areas, people depend on farming. This year there is drought and therefore people have no money.

The challenge with WhatsApp is that learners can abuse it by engaging in mischievous activities during online lessons. Cetinkaya (2017) suggests that educators have to be cautious when engaging learners through WhatsApp as studies have shown that learners' attention is diverted from learning to other issues that extend beyond academic scope. While WhatsApp can qualify as an effective ERT method, it has to be complemented by other instructional strategies so that all learners are accommodated. ERT calls for use of a variety of instructional strategies instead of sticking to only one. Today's learners are inquisitive as they would want to communicate instantly, as such, WhatsApp has become one of the most popular mobile phone applications that allows for more spontaneous engagement between learners and their teachers (Mistar \& Embi, 2016). Learners in rural areas can benefit from WhatsApp as an ERT strategy if issues of accessibility and affordability are taken into consideration.

\section{Recommendations}

The government of Zimbabwe needs to pursue diversified approaches towards implementing ERT instead of adopting a homogenous approach for the delivery of lessons in an environment characterised by variations in infrastructural and economic conditions. Strategies designed for continuity in teaching during the COVID-19 lockdown should not be taken as a permanent measure but as emergency measures that need to be implemented with speed. What is essential is having the same content delivered to learners at the same level throughout the country but not necessarily through the same modes or same approaches.

Zimbabwe needs to begin by rolling out a comprehensive strategy on remote teaching. Such a strategy should include a variety of options that suit different 
conditions. In doing this, the government should partner with other relevant organisations such as mobile network service providers that include Econet, Netone, Telecel and Powertel, among others. These mobile network service providers should partner government and work towards improving and expanding network coverage throughout the country. Private and public broadcasters should also work with government and NGOs to boost signal coverage and strength in remote areas including those that previously had no radio signal. Free online textbooks and other teaching materials must be compiled by publishing companies in collaboration with the MPSE. An extra subject focusing on COVID-19 could also be added to the curriculum. Such a subject should also be taught remotely. This subject can be named "Life and Health" and should be intended to prepare learners for the opening of schools after the lockdown. Above all, Zimbabwe should draw most of its lessons from China's experiences of conducting learning during COVID-19 lockdown, where a variety of ERT strategies were employed to include learners across all corners of the country.

Further research needs to be conducted on how ERT could be adopted in the teaching and learning of technical subjects such as linguistics, particularly phonetics and those that require practical instruction such as chemistry, physics, wood technology, technical graphics and agriculture among others. Research also needs to be carried out on the possibilities of making blended instruction to be a norm in the post-COVID-19 era.

\section{Conclusions}

The 'one size fits all' approach by the government of Zimbabwe in teaching and learning has resulted in the exclusion of the majority of learners in rural settings. In most public schools in rural areas, teaching and learning has not been taking place at all because the government has been trying to adopt a uniform approach for the whole country regardless of different ICT infrastructure and economic conditions in different geographical settings. The tendency to try and deliver lessons through the same mode or approach throughout the country has resulted in government's failure to implement teaching and learning during the COVID19 lockdown. The fear by the government to exclude learners in rural settings because of trying to adopt uniform strategies throughout the country resulted in teaching and learning not taking place at all. The major problem is that the government has been trying to implement permanent approaches to teaching, yet what is required is a simple ERT strategy. Failure to have active learning taking place in the country has resulted in the government pushing for the opening of schools at a time when the country has not yet achieved the WHO set standards for the resumption of face-to-face teaching and learning.

\section{References}

Aguliera, E., \& Nightengale-Lee, B. (2020). Emergency remote teaching across urban and rural contexts: Perspectives on educational equity. Information and Learning Sciences, 121(5), 471-474. https:/ / doi.org/10.1108/ils-04-2020-0100

Alghamdi, A. K. H., \& Al-Ghamdi, N. A. (2021). Elementary teachers' thoughts about distance education and learning 21st-century skills during COVID pandemic. 
International Journal of Teaching, Learning and Educational Research, 20(3), 33-50. https:// doi.org/10.26803/ijlter.20.3.3

Al-Naabi, I., \& Al-Abri, A. (2021). E-learning implementation barriers during COVID-19: A cross-sectional survey design. International Journal of Teaching, Learning and Educational Research, 20(8), 176-193. https://doi.org/10.26803/ijlter.20.8.11

Barakabitze, A. A., Lazaro, A. W. A., Ainea, N., Mkwizu, M. H., Maziku, H., Matofali, A. X., Iddi, A., \& Sanga, C. (2019). Transforming African education systems in science, technology, engineering, and mathematics (STEM) using ICTs: Challenges and opportunities. Education Research International. https://doi.org/10.1155/2019/6946809

Batac, K. I. T., Baquiran, J. A., \& Agaton, C. B. (2021). Qualitative content analysis of teachers' perceptions and experiences in using blended learning during the COVID-19 pandemic. International Journal of Learning, Teaching and Educational Research, 20(6), 225-243. https://doi.org/10.26803/ijlter.20.6.12

Bozkurt, A., \& Sharma, R. C. (2020). Emergency remote teaching in a time of global crisis due to coronavirus pandemic. Asian Journal of Distance Education, 15(1), i-vi. https://doi.org/10.5281/zenodo.3778083

Burzynska, K., \& Contreras, G. (2020). Gendered effects of school closures during the COVID-19 pandemic. The Lancet, 395(10242). https://doi.org/10.1016/S01406736(20)31377-5

Casey, M., Shaw, E., Whittingham, J., \& Gallava, N. (2018). Online Teaching: Tools and Techniques to Achieve Success with Learners. Rowan and Littlefield.

Cauchemez, S., Van Kerkhove, M. D., Archer, B. N., Cetron, M., Cowling, B. J., Grove, P., Hunt, D., Kojouharova, M., \& Kon, P. (2014). School closures during the 2009 influenza pandemic: National and local experiences. BMC Infectious Diseases, 14(207). https:/ / doi.org/10.1186/1471-2334-14-207

Cetinkaya, L. (2017). The impact of WhatsApp on success in education process. International Review of Research in Open and Distance Learning, 18(7), 59-74 https://doi.org/10.19173/irrodl.v18i7.3279_

Creswell, J. W. (2017). Research Design: Qualitative and Mixed Methods Approaches. Sage.

Dube, B. (2020). Rural online learning in the context of COVID-19 in South Africa: Evoking an inclusive education approach. Multidisciplinary Journal of Educational Research, 10(2), 135-157. https:// doi.org/10.4471/remie.2020.5607

Econet raises data by $225 \%$. (2020, May 05). Bulawayo24.com https:// bulawayo24.com/index-id-news-sc-national-bulawayo-184824.html

Gallo, G. \& Trompetto, M. (2020). The effects of COVID-19 on academic activities and surgical education in Italy. Journal of Investigative Surgery, 33(7), 687-689. https:// doi.org/10.1080/08941939.2020.1748147

Gono, V. (2020, April 26). Pupils to receive lessons through radio. Sunday News. https://www.sundaynews.co.zw/pupils-to-receive-lessons-through-radio/

Gwaka, L. T., May, J., \& Tucker, W. (2018). Towards low-cost community networks in rural communities: The impact of context using the case of Beitbridge, Zimbabwe. E J Info Sys Dev Countries, 84, 1-11. https://doi.org/10.1002/isd2.12029

Hodges, C., Moore, S., Lockee, B., Trust, T., \& Bond, A. (2020). The difference between emergency remote teaching and online learning. Educause Review. https://er.educause.edu/articles/2020/3/the-difference-between-emergencyremote-teaching-and-online-learning

Huang, R. H., Liu, D. J., Tlili, A., Yang, J. F., \& Wang, H. H. (2020). Handbook on Facilitating Flexible Learning during Educational Disruption: The Chinese Experience in Maintaining Undisrupted Learning in COVID-19 Outbreak. Smart Learning Institute of Beijing national University. https://alecso.org/nsite/images/1-4-2 
King, P. T., \& Londrigan, S. (2021). The 1918 influenza and COVID-19 pandemics: The effect of age on outcomes. Respirology, 26(9), 840-841.

Kriger, N. (1988). The Zimbabwean war of liberation: Struggles within the struggle. Journal of Southern African Studies, 14(2), 304-322.

Krishnan, L., Ogunwole, S. M., \& Cooper, L. A. (2020). Historical insights on Coronavirus Disease 2019 (COVID-19), the 1918 influenza pandemic, and racial disparities: Illuminating a path forward. Annals of Internal Medicine, [Ahead of print] https://doi.org/10.7326/m20-2223

Lee, W. S. \& Rhee, D. K. (2021). Corona-Cov-2 (COVID-19) and ginseng: Comparison of possible use in COVID-19 and influenza. Journal of Ginseng Research, 45(4), 535537.

Liang, S. T., Liang, L. T., \& Rosen, J. M. (2021). COVID-19: A comparison to the 1918 influenza and how we can defeat it. Postgraduate Medical Journal, 97(1147), 273274.

Mahlaba, S. C. (2020). Reasons why self-directed learning is important in South Africa during the COVID-19 pandemic. South African Journal of Education, 34(6), 120136. https://dx.doi.org/10.20853/34-6-4192

McAleer, M. (2020). Prevention is better than the cure: Risk management of COVID-19. Journal of Risk and Financial Management, 13(3): 46. https:// doi.org/10.3390/jrfm13030046

Mistar, B. I., \& Embi, M. A. (2016). Students' perception on the use of WhatsApp as a learning tool in ESL classroom. Journal of Education and Social Sciences, 4, 96-104.

Molise, H. \& Dube, B. (2020). Emergency online teaching in economic and management sciences necessitated by the COVID-19 pandemic: The need for healthy relations in a rural schooling context. International Journal of Learning, Teaching and Educational Research, 19(6), 387-400. https://doi.org/10.26803/ijlter.19.6.23

Mukuna, K. R., \& Aloka, P. J. O. (2020). Exploring educators' challenges of online learning in COVID-19 at a rural school, South Africa. International Journal of Learning, Teaching and Educational Research, 19(10), 134-149. https://doi.org/10.26803/ijlter.19.10.8

Nhongo, R. \& Tshotsho, B. P. (2021). The shortcomings of emergency remote teaching in rural settings of Zimbabwe during COVID-19 school closures: Lessons from China's experience. Africa's Public Service Delivery \& Performance Review, 9(1), a482. https://doi.org/10.4102/apsdpr.v9i1.482

Odera, F. Y. (2011). Learning English language by radio in primary schools in Kenya. USChina Education Review, 7, 960-966.

Ostashewski, N., \& Reid, D. (2013). The networked learning framework: A model for networked professional learning utilising social networking sites. In J. Keengwe, \& L. Kyei-Blankson (Eds.), Virtual Mentoring for Teachers: Online Professional Development Practices (pp. 66-83). Information Science Reference.

Owusu-Fordjour, C., Koomson, C. K., \& Hanson, D. (2020). The impact of COVID-19 on learning - The perspective of the Ghanaian student. European Journal of Educational Studies, 7(3), 88-101. https://doi.org/10.5281/zenodo.3753586

Psacharopoulos, G., Collis, V., Patrinos, H. A., \& Vegas, E. (2020). Lost wages: The COVID19 cost of school closures. World Bank Policy Report Working Paper, 9246. https:// ssrn.com/abstract $=3601422$

Ramrathan, L. (2020). School curriculum in South Africa in the COVID-19 context: An opportunity for education for relevance. Prospects, 51, 383-392. https://doi.org/10.1007/s11125-020-09490-1 
Ruzivo, (2019). Smart Learning Bringing 21st Century to Zimbabwe.

https://www.higherlifefoundation.com/ruzivo-smart-learning-bringing-21stcentury-learning-to-zimbabwe/

Scarpa, R., Caso, F., Costa, L., Passavanti, S., Vitale, M. G., Trojaniello C., Puente, A. D., \& Ascierto, P. A. (2020). May the analysis of 1918 influenza pandemic give hints to imagine the possible magnitude of corona virus disease-2019 (COVID-19)? Journal of Translational Medicine, 18(489). https:// doi.org/10.1186/512967-02002673-6

Sunil, B. (2021). Community radio as an agent of social change: A comparative study of Sangam and Namma Dhwani. Lulu Publication.

Talidong, K. J. B. (2020). Implementation of emergency remote teaching (ERT) among Philippine teachers in Xi'an, China. Asian Journal of Distance Education, 15(1), 196201. https://doi.org/10.5281/zenodo.3881825

Toquero, C. M. D. (2020). Emergency remote teaching amid COVID-19: The turning point. Asian Journal of Distance Education, 15(1), 185-188. https://doi.org/10.5281/zenodo.3881784

United Nations Children's Emergency Fund. (2020). Schools Remain Locked for more than 127 Million Children in Eastern and Southern Africa [Press release]. https://www.unicef.org/esa/press-releases/schools-remain-locked-more-127million-children-eastern-and-southern-africa

Viner, R. M., Russell, S. J., Croker, H., Packer, J., Ward, J., Stansfield, C., Mytton, O., Bonell, C., \& Booy, R. (2020). School closure and management practices during coronavirus outbreaks including COVID-19: A rapid systematic review. The Lancet Child \& Adolescent Health, 4(5), 397-404. https://doi.org/10.1016/S23524642(20)30095-X

Vehovah, V., Toepoel, V., \& Steinmetz, S. (2016). Non-probability sampling. In C. Wolf, D. Joye, T. W. Smith, \& Y. Fu (Eds.), The SAGE Handbook of Survey Methodology (pp. 329-345). SAGE Publications Limited.

Wang, C., Cheng, Z., Yue X. G., \& McAleer, M. (2020). Risk management of COVID-19 by universities in China. Journal of Risk and Financial Management, 13(36). https://doi.org/10.3390/jrfm13020036

Yamin, M. (2020). Counting the cost of COVID-19. International Journal of Information Technology, 12, 311-317. https:// doi.org/10.1007/s41870-020-00466-0

Zhang, W., Wang, Y., Yang, L., \& Wang, C. (2020). Suspending classes without stopping learning: China's education management policy in the COVID-19 outbreak. Journal of Risk and Financial Management, 13(55), 1-6. https://doi.org/10.3390/jrfm13030055 